"There is no doubt but that Napoleon is the most eminent man who has ever lived, yet it should give us pause to think that this Titan of Anarchy stands first in the thoughts of most men." In the passage just quoted we have one extremely eulogistic phrase "most eminent man" counterbalanced by another phrase of extreme disparagement "Titan of Anarchy." A similar array of favorable and unfavorable expressions can be found in any impartial biography of Napoleon. It is this peculiar blending in one man of different extremes which has given Napoleon and many other men a great share of their celebrity; in such cases the ratio of the numbers of adjectives of praise against those of dispraise fails to give a true answer to the question, which man of a given group of men is the most eminent or historically most important.

The space method and reference frequency methods of estimating fame are not open to the objections which have been raised against the adjective method. The historian in discussing, for example, the respective influence of Euripides and Sophocles upon human affairs must necessarily devote more space and make more references to Euripides since his influence in this respect was much the greater, yet in doing this he need not necessarily employ any adjectives of direct praise or dispraise.

The space method and reference frequency methods are also more free from the errors of personal equation than the adjective method. In the sentence "Cæsar was ambitious" one person might regard ambitious as a term of praise and another of dispraise, yet these two persons would agree perfectly as to the number of lines in a biographical sketch of Cæsar or as to the number of times Cæsar was referred to in an index.

In the selection of a method for estimating historical values it would seem then necessary first of all to dissociate the question of merit from that of fame, and the questions of excellence in particular directions from the broader questions of historical importance. For estimating merit and excellence in particular qualities, which is perhaps the chief concern of the critic, the adjective method proposed by Dr. Woods may possess certain advantages. But for estimating fame and historical importance, which is the chief concern of the "historiometrician," the adjective method would seem far inferior to the space and reference frequency methods.

As to the exactness of historiometry as a science, may we not say what Huxley once said of another science, the most exact of all. It " grinds your stuff of any degree of fineness, but nevertheless what you get out depends on what you put in."

\section{A. Browne}

New York City

DR. WOODS'S APPLICATION OF THE HISTOMETRIO METHOD

The paper by Dr. F. A. Woods, published in ScIEnce, April 14, giving the results of his metrical investigation of the biographies of eminent Americans is one of great interest. Both in method and results it opens fields of investigation of the highest sociological value. $\mathrm{He}$ has proved the reliability of his figures by reaching approximately the same results, for the state of Massachusetts and the other thirteen original states, when using different sets of data; and while the variation in the results indicate what would be considered in physics as a large probable error, yet they are really small considering the method used and the number of observations.

If the wide range shown thus by the different states in their production of eminent persons per thousand of their white population can not be explained by environment it is evident that the arguments for the dominance of hereditary ability will be strongly supported. On the other hand, if it can be explained by a high coefficient of skew correlation with one or more series of quantities expressing any antecedent social condition it leaves just so much less for heredity to explain. Thanks to the work of Galton and others, heredity is already mathematically expressed by the correlation of the characters of individuals in successive generations. And perhaps for that reason the tendency now is to exaggerate the 
relative importance of heredity. Dr. Woods himself, judging from his article in The Popular Science Monthly, April, 1910, has taken an extreme view of the dominance of heredity over environment, and apparently he expects the present investigation to support that view. The further publication of his results will therefore be awaited with special interest.

The first series of quantities expressing environment in youth which is suggested for correlation with the percentage of eminence in maturity is educational. The simplest measure of educational opportunity in each state is its expenditure per capita for school purposes. We do not know the average per annum, but we do know, accurately for most of the states, the public expenditure forty years ago for the education of the present generation. These data are given in Table 14 of the Report of the Commissioner of Education for the year 1910. For a first approximation we can assume that the ratio of per capita expense in the different states has been constant, and it is only with the ratio that we are concerned.

Massachusetts stands highest with $\$ 3.73$ per capita, which was more than twice the average of the whole country, and also more than twice the average of the thirteen states Dr. Woods has tabulated. Connecticut is second with \$2.74. New Hampshire stands near the average. But it is well known that private educational institutions are relatively more important in New England than in any other part of the country; while Harvard and Yale colleges would substantially raise the preeminence of Massachusetts, Connecticut, and the whole group, in the total per capita expense table, and so give them the places they have in Dr. Woods's table.

Virginia, which Dr. Woods found to be generally below the average in the table of eminence, is credited with only 47 cents in the expense table. But including West Virginia, which was not separated until 1863, the average was 86 cents.

South Carolina, which Dr. Woods found to be slightly above the average for the white population, is credited with only 38 cents per capita of the whole population. But that state had the highest percentage of colored population (60 per cent. in 1870), while forty years ago most of the school money was spent on the white schools, and in ante-bellum days of course it was all for the white population. This would raise the per capita expense to 95 cents, and give it good rank among the southern states, but still below the average of the thirteen states. Why this state should stand above the average in Dr. Woods's table remains to be explained. It shows, as we should expect, that schools do not supply all of a child's environment, and other correlations must be sought-the ratio of whose coefficients ought to be significant of their relative importance in making eminent persons.

North Carolina, which Dr. Woods found "has always had the worst record" for the production of eminence, the percentage being about one-fourth the average, is credited with only 16 cents per capita for education-this being the lowest for the thirteen states, and also for the whole country-being in fact about one tenth the average. But applying the same total expenditure to the white population the per capita expense would be 25 cents -about one sixth the average.

The average number of days of public schooling given to each inhabitant between the ages of five and eighteen years, in the school year 1870-71, in the New England and middle states was 70.2 days, and in the southern Atlantic states only 18.1 days. The per capita expense therefor was $\$ 2.38$ and 63 cents, respectively.

We seem to be near the time when the cost of encyclopedic eminence can be stated in dollars without making any reflection on the compilers of those works.

Further, if we can approximate the expense of higher as well as elementary education in each state, we can easily, by the method of least squares, determine the ratio between them which is most favorable for the production of eminent persons.

It appears that Dr. Woods has directly opened the way to the mathematical determination of the relative importance of hered- 
ity and environment. At least we may expect a flood of new light on the subject from histometrical investigations, and if the conclusion is different from what the author of the method anticipated it will not at all detract from the credit due him for its development.

BrookLyN, N. Y.

Geo. H. Johnson

\section{METALS ON METALS, WET}

To the Editor of Science: A year or two ago I repeated to a class in elementary physics the statement, familiar to generations of engineers on the authority of General Morin, supported by the approval of Rankine, that the coefficient of friction of metals on metals, wet, is considerably greater than that of metals on metals, dry.

Thereupon a thoughtful youth in the class asked me why, if this were the case, it was customary to put sand on wet car-rails to prevent the slipping of the driving-wheels. Taken aback by this unexpected scepticism, I begged for time to find the right answer to the disturbing question and set to work experimentally on the problem. The student reported after a time that trackmen had told him the water they had trouble with was usually slimy, which seemed to be a fairly satisfactory explanation of the puzzle; but meanwhile my experiments had shown some interesting facts, which I will here set forth.

Using a disk of brass, about $7.5 \mathrm{~cm}$. in diameter and about $0.6 \mathrm{~cm}$. thick, on a flat brass plate, I found:

1. That, when there was no load on the disk, a few small drops of water placed between it and the plate multiplied by a factor which might be as great as 3 the friction between the two.

2. That, when the disk was heavily loaded, the presence of the few small drops of water between it and the plate made little, if any, relative difference in the friction between the two.

3. That when plenty of water was used, so that it covered the whole space beneath the disk and extended somewhat beyond the edge, the disk without load was drawn along the plate quite as easily, apparently, as when both were dry.

From these facts I came to the conclusion that the increase of friction observed in case 1 was not due to an increase in the coefficient of friction caused by the water, but merely to the increase of pressure between the disk and the plate, caused by the suction of the capillary perimeters of the water-spots between them. When there is much water, its perimeter is outside the edge of the disk, is wide, or thick, and has little effect.

Some little search in books dealing with the subject of friction has failed to show there any recognition of this possible explanation, and refutation, of the Morin-Rankine statement of the large value of the coefficient for metals on metals, wet; but I should hardly have written you about the matter if I had not recently found this statement repeated in the "Smithsonian Physical Tables" published in 1903. I hope the new edition of these tables will not quote Rankine on this particular without further evidence.

Edwin H. HaLL

CAMBRIDGe, Mass., April 29, 1911

\section{SCIENTIFIC BOOKS}

The Stability of Truth. By David Starr JoRDan. New York, Henry Holt \& Co. 1911. Pp. 180.

"This little book," says the author, " represents the substance of a course of lectures delivered on the John Calvin McNair foundation in the University of North Carolina, January, 1910."

The chapter headings are: Reality and Science, Reality and the Conduct of Life, Reality and Monoism, Reality and Illusion, Reality and Education, Reality and Tradition.

Evidently something has happened in philosophy, in science or in both when a scientist of the first class, not to say the author of this volume in particular, puts out a book with the good old philosophical term, "Reality" at the head of every chapter. Doubtless in the minds of most scientists there will be little question about where "something has happened." 